\title{
GAMBARAN KARAKTERISTIK CALON PENGANTIN TENTANG TANDA BAHAYA ANEMIA DI PUSKESMAS MAKASAR JAKARTA TIMUR
}

\author{
*Nani Hendriani ${ }^{1)}$, Sundari Fatimah ${ }^{2)}$, Okta Zenita Siti Fatimah ${ }^{3)}$ \\ Program Studi DIII-Kebidanan, Fakultas Kesehatan, Universitas Mohammad Husni Thamrin \\ Correspondence author: nanihendriani1654@gmail.com, Jakarta, Indonesia
}

DOI: https://doi.org/10.37012/jik.v12i1.182

\begin{abstract}
ABSTRAK
Kelompok wanita usia subur rentan terhadap anemia gizi besi karena beberapa permasalahan yang dialami wanita usia subur seperti mengalami menstruasi tiap bulan, mengalami kehamilan, dan kurang asupan zat besi makanan. Kondisi inilah yang dapat memperberat anemia gizi besi pada WUS pranikah sehingga tidak dipungkiri bahwa WUS pranikah sebagai kelompok yang rawan anemia gizi besi dan membutuhkan perhatian dalam penanganannya. Dibutuhkan pemberian informasi jauh sebelum kehamilan ibu terjadi. Apabila ibu hamil mengetahui dan memahami akibat anemia dan cara mencegah anemia maka akan mempunyai perilaku kesehatan yang baik dengan harapan dapat terhindar dari berbagai akibat atau risiko dari terjadinya anemia kehamilan. Tujuan penelitian ini untuk mengetahui Gambaran Karakteristik Calon Pengantin tentang Tanda Bahaya Anemia di Puskesmas Makasar Jakarta Timur. Tahap penelitian adalah tahap (1) mengambil data penelitian dengan data sekunder Catin dari bulan Oktober 2018 - September 2019 di Puskesmas Makasar Jakarta Timur, tahap (2) Data Primer menyebarkan kuesioner kepada seluruh Catin di Puskesmas Makasar Jakarta Timur, tahap (3) analisis data. Data yang dikumpulkan meliputi karakteristik responden, yaitu data calon pengantin, umur, pendidikan, pekerjaan, lila, dan hasil pengukuran kadar hemoglobin $(\mathrm{Hb})$ darah, teknik analisis yang digunakan Uji Chi Square.
\end{abstract}

Keyword: Calon Pengantin, Tanda Bahaya Anemia.

\begin{abstract}
The group of women of childbearing age is susceptible to iron nutritional anemia because of some problems experienced by women of childbearing age such as having menstruation every month, experiencing pregnancy, and lack of food iron intake. This condition can aggravate iron nutrition anemia in premarital WUS so that it is undeniable that premarital WUS as a group that is prone to iron nutritional anemia and requires attention in handling it. Information is needed long before the mother's pregnancy occurs. If pregnant women know and understand the consequences of anemia and how to prevent anemia, they will have good health behaviors in the hope that they will be able to avoid the various consequences or risks of pregnancy anemia. The purpose of this study was to determine the Characteristics of the Prospective Bride and Groom on the Danger of Anemia Signs at the Makassar Public Health Center in Makassar.

The research phase is stage (1) taking research data with secondary data from Catin from October 2018 - September 2019 at the Makasar Health Center in East Jakarta, phase (2) Primary Data distributing questionnaires to all Catin at the Makasar Health Center in East Jakarta, stage (3) data analysis. The data collected included the characteristics of the respondents, namely the data of the prospective bride, age, education, occupation, lila, and the results of blood hemoglobin $(H b)$ measurements, analytical techniques used Chi Square Test.
\end{abstract}

Keyword: Prospective Bride, Danger Signs Of Anemia. 


\section{PENDAHULUAN}

Anemia merupakan masalah kesehatan masyarakat di seluruh dunia. Menurut data WHO secara global, kasus anemia sebanyak 1,62 miliar orang atau 24,8\% dari populasi. Berdasarkan Riskesdas 2013 terdapat 21,7\% penduduk indonesia dengan kadar hemoglobin yang kurang dari batas normal dengan proporsi 20,6\% di perkotaan dan $22,8 \%$ di pedesaan serta $18,4 \%$ laki-laki dan 23,9\% perempuan. Menurut WHO (2013) 40\% kematian ibu di negara berkembang berkaitan dengan anemia dalam kehamilan di Indonesia prevalensi anemia dalam kehamilan masih cukup tinggi yaitu $68 \%$.

Sebagian besar penyebab anemia di Indonesia adalah kekurangan zat besi yang berasal dari makanan yang dimakan setiap hari dan diperlukan untuk pembentukan hemoglobin sehingga disebut anemia kekurangan besi. Anemia zat besi banyak diderita oleh wanita hamil, wanita menyusui dan wanita usia subur, pada umumnya karena fungsi kodrati yaitu haid, hamil, melahirkan dan menyusui ${ }^{2}$.

Dampak yang ditimbulkan akibat anemia defisiensi besi sangat kompleks. Hal ini juga tentu akan berdampak pada WUS pranikah yang akan menghadapi masa kehamilan setelah menikah dan menghasilkan generasi penerus bangsa. Status anemia yang terjadi pada masa ini rentan akan mengakibatkan efek secara tidak langsung terhadap janin yang akan dikandung oleh WUS nantinya menyebabkan buruknya persalinan, berat bayi lahir rendah, bayi lahir premature, serta komplikasi kehamilan dan kelahiran ${ }^{3}$.

Banyaknya angka anemia pada ibu hamil, maka perlu diketahui status anemia ibu sebelum hamil atau pada saat sebelum menikah (calon pengantin). Berdasarkan observasi dan survei pendahuluan yang dilakukan peneliti pada tanggal 02 Oktober 2019 di Puskesmas Makasar Jakarta Timur, pada bulan Oktober 2018 sampai September 2019 ada 2380 orang calon pengantin, dimana calon pengantin perempuan adalah calon ibu hamil, yang rata-rata pendidikanya SMA, pekerjaan karyawan swasta dan umur rata-rata 20 tahun keatas. Di Puskesmas Makasar, semua calon pengantin dilakukan pemeriksaan hemoglobin (hb), menurut data pemeriksaan dari bulan Oktober 2018 - September 2019 pada calon pengantin, dimana rata-rata kadar hemoglobinya dibawah 12 gram terdapat sebanyak 162 calon pengantin ${ }^{9}$. Dari hasil uraian diatas, maka peneliti tertarik untuk mengetahui gambaran karakteristik calon pengantin tentang tanda bahaya anemia di Puskesmas Makasar Jakarta Timur ${ }^{4}$. 


\section{METODE}

Metode Penelitian adalah metode kuantitatif dengan pendekatan deskriptif karena penelitian ini bertujuan memperoleh Gambaran mengenai Karakteristik Calon Pengantin Tentang Tanda Bahaya Anemia secara studi cross sectional ${ }^{5}$. Teknik sampling yang dipilih oleh peneliti dalam penelitian ini adalah purposive sampling yaitu dengan mengambil kasus atau responden yang kebetulan ada (sesuai dengan Kriteria Inklusi): a. Semua Catin dengan Anemia $(\mathrm{Hb}<12 \mathrm{~g} / \mathrm{dl})$ dan tidak mengalamai riwayat penyakit lain di wilayah kerja Puskesmas Makassar, b. Bersedia menjadi responden penelitian, c. Bersedia mengikuti kegiatan sampai selesai.

Responden penelitian ini adalah seluruh Catin (Calon Pengantin) di Puskesmas Makassar Jakarta Timur, sedangkan respondennya adalah sebagian Catin yang telah mengisi kuesioner. Tahap penelitian adalah tahap (1) menyebarkan kuesioner kepada seluruh Catin di Puskesmas Makassar Jakarta Timur, tahap (2) analisis data. Data yang digunakan pada penelitian ini adalah data sekunder dan data primer. Data yang dikumpulkan meliputi karakteristik responden, yaitu data calon pengantin, umur, pendidikan, pekerjaan, lila dan hasil pengukuran kadar hemoglobin $(\mathrm{Hb})$ darah, teknik analisis yang digunakan yaitu analisis univariat, dan analisis bivariate (Uji Chi Square) ${ }^{6}$.

\section{HASIL DAN PEMBAHASAN}

Setelah memperoleh gambaran dari masing - masing variabel, selanjutnya dilakukan analisa bivariat untuk mengetahui gambaran karakteristik usia, pekerjaan, pendidikan, lila, kadar $\mathrm{Hb}$, dengan pengetahuan dengan menggunakan metode Chi Square $\left(X^{2}\right)$.

Tabel silang untuk melihat keeratan gambaran karakteristik usia dan pengetahuan adalah sebagai berikut :

Tabel 1. Distribusi Responden Berdasarkan Usia dan Pengetahuan

\begin{tabular}{|c|c|c|c|c|c|c|c|c|}
\hline \multirow{3}{*}{ Usia } & \multicolumn{4}{|c|}{ Pengetahuan } & \multirow{2}{*}{\multicolumn{2}{|c|}{ Total }} & \multirow{3}{*}{ OR } & \multirow{3}{*}{ P Value } \\
\hline & \multicolumn{2}{|c|}{ Tahu } & \multicolumn{2}{|c|}{ Tidak } & & & & \\
\hline & $\mathbf{n}$ & $\%$ & $\mathbf{n}$ & $\%$ & $\mathbf{n}$ & $\%$ & & \\
\hline $22-35$ & 33 & 80,5 & 8 & 19,5 & 41 & 100 & & \\
\hline$<21$ & 11 & 68,8 & 5 & 31,3 & 16 & 100 & 1.605 & 0.448 \\
\hline$>35$ & 3 & 60 & 2 & 40 & 5 & 100 & & \\
\hline Jumlah & 47 & 75,8 & 15 & 24,2 & 62 & 100 & & \\
\hline
\end{tabular}


Tabel silang 1. tentang gambaran karakteristik usia dan pengetahuan, menunjukkan bahwa ada 33 dari $41(80,5 \%)$ responden yang termasuk kategori usia 22 - 35 pengetahuan ya (tahu) tentang tanda bahaya anemia dan ada 5 dari $16(31,3 \%)$ responden yang termasuk kategori usia $<21$ pengetahuan tidak tahu tentang tanda bahaya anemia. Sementara ada 11 dari $16(68,8 \%)$ responden yang termasuk kategori usia < 21 pengetahuan ya (tahu) tentang tanda bahaya anemia dan ada 8 dari $41(19,5 \%)$ responden yang termasuk kategori usia 22 - 35 pengetahuan tidak tahu tentang tanda bahaya anemia. Sedangkan ada 3 dari 5 (60\%) responden yang termasuk kategori usia > 35 pengetahuan ya (tahu) tentang tanda bahaya anemia dan ada 2 dari $5(40 \%)$ responden yang termasuk kategori usia > 35 pengetahuan tidak tahu tentang tanda bahaya anemia. Hasil uji statistik dengan Chi Square dinilai P value =0,448 lebih besar dari $\alpha=0,05$ maka Ho diterima, sehingga dapat disimpulkan bahwa tidak ada hubungan yang bermakna antara usia dan pengetahuan.

Tabel silang untuk melihat keeratan gambaran karakteristik pekerjaan dan pengetahuan adalah sebagai berikut :

Tabel 2. Distribusi Responden Berdasarkan Pekerjaan dan Pengetahuan

\begin{tabular}{|c|c|c|c|c|c|c|c|c|}
\hline \multirow{3}{*}{ Pekerjaan } & \multicolumn{4}{|c|}{ Pengetahuan } & \multirow{2}{*}{\multicolumn{2}{|c|}{ Total }} & \multirow{3}{*}{$\mathbf{O R}$} & \multirow{3}{*}{ P Value } \\
\hline & \multicolumn{2}{|c|}{ Tahu } & \multicolumn{2}{|c|}{ Tidak } & & & & \\
\hline & $\mathbf{n}$ & $\%$ & $\mathbf{n}$ & $\%$ & $\mathbf{n}$ & $\%$ & & \\
\hline $\mathrm{Ya}$ & 37 & 78,7 & 10 & 66.7 & 47 & 75,8 & 1.850 & \\
\hline Tidak & 10 & 21,3 & 5 & 33,3 & 15 & 24,2 & $0,514-6,659$ & 0.546 \\
\hline Jumlah & 47 & 100 & 15 & 100 & 62 & 100 & & \\
\hline
\end{tabular}

Tabel silang 2. tentang gambaran karakteristik pekerjaan dan pengetahuan, menunjukkan bahwa ada 37 dari $47(78,7 \%)$ responden yang termasuk kategori bekerja pengetahuan ya (tahu) tentang tanda bahaya anemia dan ada 5 dari 15 (33,3\%) responden yang termasuk kategori tidak bekerja pengetahuan tidak tahu tentang tanda bahaya anemia. Sementara ada 10 dari $15(21,3 \%)$ responden yang termasuk kategori tidak bekerja pengetahuan ya (tahu) tentang tanda bahaya anemia dan ada 10 dari 47 (66,7\%) responden yang termasuk kategori bekerja pengetahuan tidak tahu tentang tanda bahaya anemia. Hasil uji statistik dengan Chi Square dinilai P value =0,546 lebih besar dari $\alpha=0,05$ maka Ho diterima, sehingga dapat disimpulkan bahwa tidak ada hubungan yang bermakna antara pekerjaan dan pengetahuan. 
Tabel silang untuk melihat keeratan gambaran karakteristik pendidikan dan pengetahuan adalah sebagai berikut :

Tabel 3. Distribusi Responden Berdasarkan Pendidikan dan Pengetahuan

\begin{tabular}{|c|c|c|c|c|c|c|c|c|}
\hline \multirow{3}{*}{ Pendidikan } & \multicolumn{4}{|c|}{ Pengetahuan } & \multirow{2}{*}{\multicolumn{2}{|c|}{ Total }} & \multirow{3}{*}{ OR } & \multirow{3}{*}{ P Value } \\
\hline & \multicolumn{2}{|c|}{ Tahu } & \multicolumn{2}{|c|}{ Tidak } & & & & \\
\hline & $\mathbf{n}$ & $\%$ & $\mathbf{n}$ & $\%$ & $\mathbf{n}$ & $\%$ & & \\
\hline Tinggi & 42 & 89.4 & 13 & 86.7 & 55 & 88.7 & 1.292 & 1 \\
\hline Rendah & 5 & 10.6 & 2 & 13.3 & 7 & 11.3 & $0.224-7.465$ & 1 \\
\hline Jumlah & 47 & 100 & 15 & 100 & 62 & 100 & & \\
\hline
\end{tabular}

Tabel silang 3. tentang gambaran karakteristik pendidikan dan pengetahuan, menunjukkan bahwa ada 42 dari 55 (89,4\%) responden yang termasuk kategori pendidikan tinggi pengetahuan ya (tahu) tentang tanda bahaya anemia dan ada 2 dari 7 $(13,3 \%)$ responden yang termasuk kategori pendidikan rendah pengetahuan tidak tahu tentang tanda bahaya anemia. Sementara ada 5 dari $7(10,6 \%)$ responden yang termasuk kategori pendidikan rendah pengetahuan ya (tahu) tentang tanda bahaya anemia dan ada 13 dari $55(86,7 \%)$ responden yang termasuk kategori pendidikan tinggi pengetahuan tidak tahu tentang tanda bahaya anemia. Hasil uji statistik dengan Chi Square dinilai P value $=1$ lebih besar dari $\alpha=0,05$ maka Ho diterima, sehingga dapat disimpulkan bahwa tidak ada hubungan yang bermakna antara pedidikan dan pengetahuan.

Tabel silang untuk melihat keeratan gambaran karakteristik Lila dan pengetahuan adalah sebagai berikut :

Tabel 4. Distribusi Responden Berdasarkan LILA dan Pengetahuan

\begin{tabular}{|c|c|c|c|c|c|c|c|c|}
\hline \multirow{3}{*}{ LILA } & \multicolumn{4}{|c|}{ Pengetahuan } & \multirow{2}{*}{\multicolumn{2}{|c|}{ Total }} & \multirow{3}{*}{ OR } & \multirow{3}{*}{ P Value } \\
\hline & \multicolumn{2}{|c|}{ Tahu } & \multicolumn{2}{|c|}{ Tidak } & & & & \\
\hline & $\mathbf{n}$ & $\%$ & $\mathbf{n}$ & $\%$ & $\mathbf{n}$ & $\%$ & & \\
\hline$>23.5$ & 33 & 70.2 & 12 & 80 & 45 & 72.6 & & \\
\hline$<23.5$ & 14 & 29.8 & 3 & 20 & 17 & 27.4 & $\begin{array}{c}0.589 \\
0.144-2.417\end{array}$ & 0.684 \\
\hline Jumlah & 47 & 100 & 15 & 100 & 62 & 100 & & \\
\hline
\end{tabular}

Tabel silang 4. tentang gambaran karakteristik Lila dan pengetahuan, menunjukkan bahwa ada 33 dari $45(70,2 \%)$ responden yang termasuk kategori lila > 23,5 cm pengetahuan ya (tahu) tentang tanda bahaya anemia dan ada 3 dari 17 (20\%) responden yang termasuk kategori lila $<23,5 \mathrm{~cm}$ pengetahuan tidak tahu tentang tanda bahaya anemia. Sementara ada 14 dari $17(29,8 \%)$ responden yang termasuk kategori lila < 23,5 cm pengetahuan ya (tahu) tentang tanda bahaya anemia dan ada 12 dari 45 (80\%) responden yang termasuk 
kategori lila $>23,5 \mathrm{~cm}$ pengetahuan tidak tahu tentang tanda bahaya anemia. Hasil uji statistik dengan Chi Square dinilai P value $=0,684$ lebih besar dari $\alpha=0,05$ maka Ho diterima, sehingga dapat disimpulkan bahwa tidak ada hubungan yang bermakna antara lila dan pengetahuan.

Tabel silang untuk melihat keeratan gambaran karakteristik Kadar $\mathrm{Hb}$ dan pengetahuan adalah sebagai berikut :

Tabel 5. Distribusi Responden Berdasarkan Kadar HB dan Pengetahuan

\begin{tabular}{|c|c|c|c|c|c|c|c|c|}
\hline \multirow{3}{*}{ HB } & \multicolumn{4}{|c|}{ Pengetahuan } & \multirow{2}{*}{\multicolumn{2}{|c|}{ Total }} & \multirow{3}{*}{ OR } & \multirow{3}{*}{ P Value } \\
\hline & \multicolumn{2}{|c|}{ Tahu } & \multicolumn{2}{|c|}{ Tidak } & & & & \\
\hline & $\mathbf{n}$ & $\%$ & $\mathbf{n}$ & $\%$ & $\mathbf{n}$ & $\%$ & & \\
\hline Normal & 28 & 59.6 & 9 & 60 & 37 & 59.7 & 0.982 & \\
\hline Tidak normal & 19 & 40.4 & 6 & 40 & 25 & 40.3 & $\begin{array}{l}0.300- \\
3.216\end{array}$ & 1 \\
\hline Jumlah & 47 & 100 & 15 & 100 & 62 & 100 & & \\
\hline
\end{tabular}

Tabel silang 5. tentang gambaran karakteristik Kadar $\mathrm{Hb}$ dan pengetahuan, menunjukkan bahwa ada 28 dari $37(59,6 \%)$ responden yang termasuk kategori kadar $\mathrm{Hb}$ normal pengetahuan ya (tahu) tentang tanda bahaya anemia dan ada 6 dari 25 (40\%) responden yang termasuk kategori kadar $\mathrm{Hb}$ tidak normal pengetahuan tidak tahu tentang tanda bahaya anemia. Sementara ada 19 dari 25 (40,4\%) responden yang termasuk kategori kadar $\mathrm{Hb}$ tidak normal pengetahuan ya (tahu) tentang tanda bahaya anemia dan ada 9 dari $37(60 \%)$ responden yang termasuk kategori kadar $\mathrm{Hb}$ normal pengetahuan tidak tahu tentang tanda bahaya anemia. Hasil uji statistik dengan Chi Square dinilai $\mathrm{P}$ value $=1$ lebih besar dari $\alpha=0,05$ maka Ho diterima, sehingga dapat disimpulkan bahwa tidak ada hubungan yang bermakna antara kadar $\mathrm{Hb}$ dan pengetahuan.

Jika dilihat dari segi umur, calon pengantin yang termasuk kategori usia 22-35 tahun sebanyak 33 dari 41 orang $(80,5 \%)$ pengetahuan ya (tahu) tentang tanda bahaya anemia. Secara umum kemungkinan terjadi anemia bisa pada usia berapapun. Usia reproduksi yang sehat bagi seorang wanita untuk hamil dan melahirkan yaitu 20-35 tahun, karena pada usia ini alat reproduksi sudah cukup matang dan siap untuk proses kehamilan dan persalinan.

Jika dilihat dari segi pendidikan, calon pengantin yang termasuk kategori pendidikan tinggi sebanyak 42 dari 55 orang $(89,4 \%)$ pengetahuan ya (tahu) tentang tanda bahaya anemia. Menurut Koentjoroningrat pendidikan seseoarang berpengaruh pada pengetahuannya, dimana semakin tinggi tingkat pendidikan seseorang makin banyak pula 
pengetahuan yang dimiliki. Sebaliknya, pendidikan yang kurang akan menghambat perkembangan sikap seseorang terhadap nilai baru yang diperkenalkan sehingga pengetahuan juga kurang ${ }^{7}$.

Jika dilihat dari segi pekerjaan, calon pengantin yang termasuk kategori bekerja sebanyak 37 dari 47 orang $(78,7 \%)$ pengetahuan ya (tahu) tentang tanda bahaya anemia. Karena pada wanita bekerja cenderung lebih mampu membeli kebutuhannya dan memperhatikan pola makannya seperti daging, ikan, telur, tempe, sayur, buah itu tercukupi.

Menurut Soemantri, bahwa anemia yang tinggi akan berdampak pada penurunan kualitas sumber daya manusia, sosial dan ekonomi ${ }^{8}$. Anemia pada calon pengantin dapat menyebabkan mudah lelah, kapasitas fisik turun, badan lemah, dan menurunya produktifitas, dan akan semakin berat kondisinya bila calon pengantin hamil. Kehamilan membutuhkan lebih banyak jumlah zat besi untuk pertumbuhan dan perkembangan janinnya, maka akan berdampak pada abortus, persalinan prematur, hambatan tumbuh kembang janin dalam rahim, mudah terjadi infeksi, pada saat persalinan bisa terjadi gangguan His, kala 1 lama, kala II berlangsung lama, dan dapat terjadi perdarahan post partum, dan pada saat nifas juga bisa terjadi sub involusi uteri menimbulkan perdarahan, infeksi puerperium, pengeluaran asi berkurang, anemia kala nifas dan mudah terjadi infeksi mamae ${ }^{9}$.

\section{SIMPULAN}

Hasil dari penelitian Gambaran Karakteristik pada calon pengantin di Puskesmas Makasar Jakarta Timur, dapat di simpulkan :

Bahwa responden kategori usia 22-35 tahun sebanyak 33 dari 41 orang (80,5\%), kategori pendidikan tinggi sebanyak 42 dari 55 orang $(89,4 \%)$, kategori bekerja sebanyak 37 dari 47 orang $(78,7 \%)$, kategori lila $>23,5$ sebanyak 33 dari 45 (70,2\%), kategori kadar $\mathrm{Hb}$ normal sebanyak 28 dari $37(59,6 \%)$ dengan pengetahuan ya (tahu) tentang tanda bahaya anemia, seperti: merasa sangat lemah atau pusing hebat hingga pingsan, tangan dan kaki terasa dingin, kulit terlihat pucat atau kekuningan, jantung berdebar, sesak nafas, hingga nyeri dada. Diharapkan penelitian ini dapat memberikan informasi tentang status anemia pada calon pengantin, sehingga sebelum menikah dapat mempertimbangkan usia, pendidikan, pekerjaan dan mempersiapkan kehamilannya lebih matang. 


\section{UCAPAN TERIMA KASIH}

Terima kasih kepada Kepala Program Studi D3 Kebidanan Universitas Mohammad Husni Thamrin, Kepala LPPM, Kepala Puskesmas Makasar Jakarta Timur, dan semua pihak yang telah banyak memberikan bantuan dalam penyelesaian penelitian ini.

\section{REFERENSI}

1. World Health Organization. Prevalence of anaemia in pregnancy. 2013 (diunduh 1 Agustus 2019). Tersedia dari: http://data.worldbank.org/indicator/ SH.PRG.ANEM.

2. Masrizal. Anemia Defisiensi Besi. Jurnal Kesehatan Masyarakat UNAND. 2007, II (1): $140: 1$

3. Hanung A, Risnawati I. Dampak Anemia Kehamilan Terhadap Perdarahan Post Partum. STIKES Muhammadiyah Kudus. Vol. 6, No. 3, 2015 : 58:1

4. Data Puskesmas Makasar. Data Catin Anemia Puskesmas Makasar. Kota Jakarta Timur: 2019.

5. Notoatmojo S. Pendidikan dan Perilaku Kesehatan. PT. RINEKA CIPTA: 2010.

6. Slamet, Sastroasmoro. Dasar-Dasar Metodologi Penelitian Klinis. Jakarta: Sagung Seto; 2011.

7. Koentjoroningrat. Pengantar Ilmu Antropologi. Jakarta: Rineka Cipta. 2009.

8. Soemantri AG, Triasih S. Anemia Defisiensi Besi: epidemiology and cognitive in children with iron deficiency anemia. Yogyakarta: Medika-fakultas kedokteran UGM. 2005: 10-25.

9. Saifudin AB. Rachimhadhi. Ilmu Kebidanan Sarwono Prawirohardjo Jakarta:. PT Bina Pustaka Sarwono Prawirohardjo. 2000.

10. Nadesul Hendrawan. Buku Sehat Calon Pengantin dan Keluarga Muda. Jakarta: Penerbit Buku Kompas. 2007.

11. Hastono PS, Sahar J, Aisah S. Pengaruh Edukasi Kelompok Sebaya Terhadap Perubahan Perilaku Pencegahan Anemia Gizi Besi pada Wanita Usia Subur di Kota Semarang. http:// jurnal.unimus.ac.id. $2010: 120: 1$

12. Waryono. 2010. Gizi Reproduksi. Yogyakarta: Pustaka Rihan.

13. Profil Kesehatan Indonesia. Program Pemberian Tablet Zat Besi di Indonesia. Jakarta: Kemenkes RI; 2014.

14. Hidayah N. Analisis Faktor Penyebab Anemia Wanita Usia Subur di Desa Jepang Pakis Kabupaten Kudus. Stikes Muhammadiyah Kudus. ISSN 2407-9189, 2016 :72:1

15. Kim, J.Y., et al. 2014. Relationship between Socioeconomic Atatus and Anemia Prevalence in Adolescent Girls based on the Fourth and Fifth Korea National Health and Nutrition Examination Surveys. European Journal of Clinical Nutrition, 68:253258. 